\title{
Powdery Mildew Severity as a Function of Canopy Density: Associated Impacts on Sunlight Penetration and Spray Coverage
}

\author{
Craig N. Austin, ${ }^{1 *}$ Gary G. Grove, ${ }^{2}$ James M. Meyers, ${ }^{3}$ \\ and Wayne F. Wilcox ${ }^{1}$
}

\begin{abstract}
Variable canopy densities and associated differences in sunlight distribution within the fruit zones on clusters were quantified and correlated with variable severities of powdery mildew within vineyards in the states of New York, Washington, and South Australia. Canopy density was measured with enhanced point quadrat analysis (EPQA), and the number of shading layers and the photon flux within the fruit zone of individual vines indicated that less disease developed on clusters with more exposure to sunlight. When clusters were categorized as heavily shaded ( $\leq 10 \%$ photosynthetic photon flux), moderately exposed, or well exposed ( $\geq 51 \%$ photosynthetic photon flux), vines with the least disease were also shown to have a significantly greater proportion of clusters in the well-exposed category relative to vines with the highest powdery mildew ratings. Consequently, these latter vines had significantly more heavily shaded clusters. The correlation remained strong and the relationship linear even with biweekly applications of either $2 \mathrm{~kg} / \mathrm{ha}$ or $9 \mathrm{~kg} / \mathrm{ha}$ of wettable sulfur during the growing season. Additionally, through the use of a fluorescent tracer and EPQA assessments, the deposit of spray materials on clusters was shown to be linearly related to their degree of exposure. Thus, canopy management practices designed to optimize sunlight exposure of grape clusters for fruit quality purposes should also significantly assist in the management of powdery mildew.
\end{abstract}

Key words: canopy management, integrated pest management, oidium

Many of the complex and interacting chemical and physiological processes in grapevines are affected by sunlight. Numerous studies have examined the effects of sunlight on various vine functions but have focused almost exclusively on basic components of physiology and/or issues pertaining to crop yield and quality. Interactions of sunlight with vine-associated microbes, including those that are known pathogens of this host (Keller et al. 2003) have received relatively little attention despite their economic importance.

The ultraviolet (UV) component of solar radiation, in particular the UV-B spectrum (290 to $320 \mathrm{~nm}$ wavelength), has been studied for its many biological effects on a wide

\footnotetext{
'Department of Plant Pathology and Plant-Microbe Biology, Cornell University, New York State Agricultural Experiment Station, Geneva, NY 14456; ${ }^{2}$ Department of Plant Pathology, Washington State University, Irrigated Agriculture Research and Extension Center, Prosser, WA 99350; and ${ }^{3}$ Department of Horticulture, Cornell University, New York State Agricultural Experiment Station, Geneva, NY 14456.

*Corresponding author (email: cna8@cornell.edu)

Acknowledgments: This work was supported in part by grants from the USDA Viticulture Consortium-East, the Lake Erie Regional Grape Program, the Grape Production Research Fund, and the New York Wine and Grape Foundation.

The authors gratefully thank Trevor Wicks, Michael McCarthy, and Peter Magarey of the South Australian Research and Development Institute for their technical advice and assistance in our Australian trials.

Manuscript submitted Jul 2010, revised Oct 2010, accepted Oct 2010

Copyright (C) 2011 by the American Society for Enology and Viticulture. All rights reserved.

doi: 10.5344/ajev.2010.10077
}

range of living organisms. Furthermore, much of the recent literature has stressed the need for increased study of the effects of UV-B radiation in agricultural systems because of current decreases in its stratospheric filtering (Björn 2007, Manning and von Tiedemann 1995, Keller 2010). UV-B can alter fungal populations on plant leaves (Moody et al. 2001), alter grapevine physiology (Kolb et al. 2001, Keller and Torres-Martinez 2004), and generally increase fungal mortality (Björn 2007, Rotem et al. 1985). Although the response to UV-B radiation is specific for individual organisms and their interactions, the majority of studies involving plant pathogens have shown a negative effect of UV-B exposure on their growth (Roberts and Paul 2006).

An additional sunlight-associated factor that can alter microclimates relevant to plant pathogen-host interactions is an increase in the surface temperature of exposed tissues. Exposure to sunlight can increase plant surface temperatures 5 to $15^{\circ} \mathrm{C}$ above ambient air temperature, as has been reported on grapes (Kliewer and Lider 1968, Smart and Sinclair 1976, Millar 1972, Downey et al. 2006) and other fruit crops (Chen et al. 2009, Ferguson et al. 1998, Schroeder 1965). These studies, however, have focused on the physiological effects on the fruit, not on the consequence of elevated temperatures on microorganisms growing on the sunlight-exposed surfaces.

Powdery mildew, caused by the fungus Erysiphe necator (Schw.) Burr., is a disease common throughout grapegrowing regions worldwide. Virtually all cultivars of Vitis vinifera, a species of European origin that evolved in isolation 
of this native North American pathogen, are highly susceptible to $E$. necator, and if left uncontrolled the fungus can destroy infected leaves and fruit. Although E. necator grows well at temperatures as high as $28^{\circ} \mathrm{C}$, it ceases growth at $32^{\circ} \mathrm{C}$ and can begin to die above $35^{\circ} \mathrm{C}$, depending on the duration of exposure (Delp 1954). Erysiphe necator development, which occurs primarily on the surface of infected tissues, is also hindered by exposure to UV-B radiation (Willocquet et al. 1996).

Several studies have shown that sunlight exposure can impact the development of grapevine powdery mildew. Basal leaf removal around fruit clusters, intended to benefit fruit quality, resulted in reduced powdery mildew severity on these berries (Chellemi and Marois 1992); the authors hypothesized that this effect was due to improved pesticide coverage and inferred that leaf removal produced a berry microclimate less conducive for disease development. One study demonstrated that a training system and row spacing that improved sunlight exposure on clusters was associated with reduced powdery mildew severity on fruit and concluded that this disease reduction was a direct effect of the increased light intensity (Zahavi et al. 2001). Vines exposed to sunlight from which UV radiation was filtered had significantly more powdery mildew than those exposed to unfiltered sunlight, which the authors attributed to associated differences in the disease susceptibility of the vines (Keller et al. 2003).

In a separate set of studies, we confirmed that sunlight exposure can reduce powdery mildew development pronouncedly because of the negative individual and synergistic effects on the fungus of (1) UV-B radiation and (2) elevated temperatures of the exposed grapevine tissues (Austin 2010, Austin et al. 2009). The objective here was to determine to what extent variable fruit exposure resulting from variable canopy densities might be operative in vineyards and climates as disparate as those in the northeastern and northwestern regions of the United States and two viticultural districts of South Australia and how these effects might relate to disease management and fungicide use practices.

\section{Materials and Methods}

Canopy and disease measurements. In all vineyards, canopy measurements were performed according to an enhanced version of the point quadrat analysis (PQA) technique originally adapted for grapevines (Smart and Robinson 1991). This enhanced point quadrat analysis (EPQA) system provides improved acuity of spatial estimates of sunlight distribution on fruit (Meyers and Vanden Heuvel 2008). We focused on two metrics calculated with EPQA: cluster exposure layer (CEL), defined as the number of shading layers between clusters and the nearest canopy boundary, and cluster exposure flux availability (CEFA), defined as the proportion of above-canopy photosynthetic photon flux (PPF) that reaches clusters.

To calculate CEL and CEFA, PQA measurements were collected using a thin, stiff rod inserted into the fruiting zone of the canopy parallel to the ground and perpendicular to the row, every $20 \mathrm{~cm}$ along the length of a vine. As the rod was inserted, each leaf or cluster contact with the leading tip of the rod was noted. Sunlight measurements were taken with an AccuPAR LP-80 Ceptometer (Decagon Devices, Pullman, WA) for each vine between 10:00 and 14:00 hr on the same day of PQA assessment. The ceptometer incorporated measurements obtained by holding the probe $(90$ $\mathrm{cm}$ long with 80 photosensors) within the vine fruit zone and parallel to the row with those obtained simultaneously above the canopy using a photosynthetically active radiation (PAR) sensor connected to the integrated controller. For each vine, 10 measurements were made over a period of $\sim 10 \mathrm{sec}$ and mean values for above- and within-canopy PPF were recorded. PQA measurements and the sunlight readings taken above and within the canopy were then used to calculate CEL and CEFA values via EPQA as described elsewhere (Meyers and Vanden Heuvel 2008). Unless otherwise noted, CEL and CEFA values are reported based on relevant measures for individual vines and analyzed with respect to disease severity ratings from the same individual vines.

Disease severity was assessed by visually estimating the percentage of the cluster area colonized by the pathogen. Unless otherwise noted, disease severities reported are vine averages calculated from 10 clusters (five per each side of the vine) arbitrarily selected to provide a representative sample.

Washington vineyard. The Washington State vineyard is located in Prosser, in the Yakima Valley (lat.: 46 $17^{\prime} 40^{\prime \prime}$; long.: $\left.-119^{\circ} 44^{\prime} 26^{\prime \prime}\right)$. Trials were conducted during the 2008 and 2009 seasons at the Irrigated Agriculture Research and Extension Center in an own-rooted, north-south oriented Vitis vinifera Chardonnay vineyard, within which vine size was highly variable. Twelve rows of 30 vines (five 6 -vine panels) each, trained to a midwire cordon with a single catch wire, were selected and natural powdery mildew infections were allowed to occur. The 12 rows were grouped into four replicate blocks of three adjacent rows each, and each row was randomly assigned a fungicide application regime at the beginning of each season. Fungicide treatments consisted of wettable sulfur (Microthiol Disperss; Cerexagri-Nisso, King of Prussia, PA; 80\% active ingredient) applied biweekly with a hooded boom sprayer at three rates: $2.24 \mathrm{~kg} / \mathrm{ha}, 8.96 \mathrm{~kg} / \mathrm{ha}$, or none. Water volumes in 2008 were $673 \mathrm{~L} /$ ha on $10 \mathrm{Jun}, 25 \mathrm{Jun}$, and $9 \mathrm{Jul}$; and 841 L/ha on $23 \mathrm{Jul}, 7 \mathrm{Aug}, 20 \mathrm{Aug}$, and 2 Sep. In 2009, volumes were $580 \mathrm{~L} /$ ha on $30 \mathrm{May} ; 767 \mathrm{~L} /$ ha on $8 \mathrm{Jun} ; 963$ $\mathrm{L} /$ ha on $22 \mathrm{Jun}$; and $1346 \mathrm{~L} / \mathrm{ha}$ on $6 \mathrm{Jul}, 20 \mathrm{Jul}$, and 3 Aug. On 4 to 8 Aug 2009 (veraison, approximately), EPQA measurements and disease assessments for 10 clusters were conducted on the second and fifth vine in each of the five panels per row, as described above. On 10 to 13 Sep 2008 (preharvest), the same techniques were used, but canopy structure was assessed on the center four vines in each of five panels per row and disease severity was assessed on 10 arbitrarily chosen clusters across the same four vines. Data are reported as mean values from each of the 15 panels per 
treatment thus assessed. Data were analyzed by regression analysis using GLM/ANOVA. Comparison of means for the effect of sulfur in Washington was made using the TukeyKramer HSD test. These and all other statistical analyses were made using JMP statistical software (SAS Institute, Cary, NC).

Dresden, New York vineyard. The Dresden vineyard is located in the Finger Lakes region of New York (lat.: $42^{\circ} 42^{\prime} 58^{\prime \prime}$; long.: $\left.-76^{\circ} 58^{\prime} 48^{\prime \prime}\right)$. The trial was conducted in 2008 in a commercial vineyard of Chardonnay vines planted in 1988 on 3309C rootstock trained to a modified Umbrella-Kniffen system with 3-m row spacing and 2-m vine spacing. Five clusters each on 22 vines were arbitrarily selected and inoculated with a suspension of E. necator conidia at $75 \%$ capfall. Cultures used for inoculum were sourced from field populations of E. necator collected from local vineyards and maintained year round on 1- to 3-month-old Riesling seedlings in the greenhouse; during the growing season, conidia for inoculations were multiplied on 2-month-old Riesling seedlings maintained in a covered shadehouse. Inoculum was prepared in the field by agitating sporulating leaves in $50-\mathrm{mL}$ Falcon tubes with $0.005 \%$ Tween solution in $\mathrm{dH}_{2} 0$, and was applied at a rate of $1 \mathrm{~mL}$ per inoculated cluster using a small spray-paint apparatus (Preval, Yonkers, NY). Subsequent quantification in the lab with the aid of a hemocytometer revealed concentrations of $5 \times 10^{4}$ to $1 \times 10^{5}$ conidia per mL. Fungal diseases on these vines were managed from bloom to final disease assessment with minimal sprays of mancozeb and a highly refined petroleum oil (Stylet-Oil, JMS Flower Farms, Vero Beach, FL), chosen for their relative lack of activity against E. necator and minimal residual/vapor activity, respectively; inoculated clusters were protected within individual plastic bags during each application. Bags were removed immediately after sprays had dried. On 18 Aug 2008 (veraison, approximately), canopy structure on all 22 vines was assessed via EPQA and all inoculated clusters were evaluated for powdery mildew severity, as described above.

Geneva, New York vineyard. The Geneva vineyard is located in New York (lat.: 42 $52^{\prime} 43^{\prime \prime}$; long.: $-77^{\circ} 0$ '51"). The trial was conducted on Chardonnay vines on 3309C rootstock, planted in 2004 and trained to a vertical shootpositioned system with 3-m row spacing and 2-m vine spacing. In the early spring of 2009, nine panels of four vines each were selected and cane pruned to 20,40, or 60 buds per vine to induce canopy variability among treatments. Each plot consisted of a single panel and treatments were arranged in a randomized complete block design, with three replications. During the subsequent growing season, natural powdery mildew infection was allowed to occur; vines were sprayed with mefanoxam and mancozeb to limit other fungal diseases, but no chemicals active against $E$. necator were applied. Canopy structure of all vines and disease severity on 10 arbitrarily chosen clusters per vine were assessed on 9 Jul 2009 (bunch closure, approximately), due to rapid degradation of the most heavily diseased berries and the development of botrytis bunch rot. Data for indi- vidual variables are reported as mean values from each of the nine individual panels examined. Data from the Geneva and Dresden trials were analyzed with simple linear regression/ANOVA.

Barossa Valley, South Australia vineyard. The Barossa vineyard is located in Nuriootpa, South Australia (lat.: $-34^{\circ} 28^{\prime} 28^{\prime \prime}$; long.: $\left.139^{\circ} 0^{\prime} 24^{\prime \prime}\right)$. The trial used two 72 -vine rows in an own-rooted cv. Chardonnay vineyard planted in 1994 with $3.5-\mathrm{m}$ row spacing and $2.25-\mathrm{m}$ vine spacing. Vines were grown on a three-wire single curtain, nonshoot-positioned trellis; pruned to two-bud spurs ( $\sim 40$ buds/ vine); and left unsprayed during the 2008-2009 growing season, allowing natural infection to occur. Canopy structure and cluster disease severity were assessed for alternating vines in each row on $10 \mathrm{Feb} 2009$, as described above.

Riverland, South Australia vineyard. The Riverland vineyard is located in Loxton, South Australia (lat.: $-34^{\circ} 26^{\prime} 24^{\prime \prime}$; long.: $\left.140^{\circ} 35^{\prime} 37^{\prime \prime}\right)$. The 2008-2009 trial was conducted in a vineyard consisting of two rows, each containing twelve 33-yr-old Chardonnay vines with divided canopies. Vines in the first row had parallel bilateral cordons stacked with $\sim 0.5 \mathrm{~m}$ spacing between cordons, vertically splitting the canopy. Vines in the second row had parallel bilateral cordons $\sim 1 \mathrm{~m}$ apart, horizontally dividing the canopy. All vines were unsprayed and natural infection was allowed to occur. Canopy structure and disease severity were assessed on 13 Feb 2009 for every vine in both rows, as described above.

Weather data. Weather data for the Washington site were obtained from AgWeatherNet (Washington Agricultural Weather Network V2.0, WSU Prosser, A12 station; $\mathrm{http} / / /$ weather.wsu.edu) located $\sim 50 \mathrm{~m}$ from the vineyard. Data for the New York sites were obtained from the N.Y. State Agricultural Experiment Station weather station in Geneva, $\sim 15 \mathrm{~km}$ north of the Dresden vineyard and $\sim 1 \mathrm{~km}$ west of the Geneva vineyard. Data for the Barossa Valley site were obtained from the Nuriootpa Research Center weather station, located $\sim 100 \mathrm{~m}$ from the vineyard. Data for the Riverland site were not available. Seasonal weather was defined as the time between 1 Apr and 31 Oct for northern hemisphere vineyards and 1 Sept to 31 Mar for Australia. Growing degree days (GDD) were calculated using daily mean temperatures and a base of $10^{\circ} \mathrm{C}$. Total solar radiation for the growing season was calculated by summing total solar radiation values for each day. Total precipitation for the growing season was calculated by summing the daily precipitation measures (Table 1).

Spray coverage efficiency. In the Geneva vineyard, four weeks after bloom in 2009 a highly soluble fluorescent dye (Pyranine 10G; Keystone Aniline Corp., Chicago, IL) was applied at a concentration of $500 \mathrm{mg} / \mathrm{L}$ in $468 \mathrm{~L} / \mathrm{ha}$ water, using a DP300 FMC airblast sprayer with a modified tower fitted with hollow cone nozzles (model TX8004VK; TeeJet, Wheaton, IL). The sprayer operated at a pressure of $70 \mathrm{kPa}$ and traveled at a speed of $5 \mathrm{kph}$. After the application had dried, one arbitrarily chosen cluster from each of the four vines per panel was harvested, placed into a plastic 
bag, and transported in a cooler to the laboratory for residue analysis. In the lab, dye was washed from individual clusters in a standard volume of deionized water in a graduated cylinder, and the volume of the cluster was determined based upon the displaced volume of water. These washings were analyzed in a Chameleon multiwell platereader (Hidex, Turku, Finland) set to read fluorescence with a $360 \mathrm{~nm}$ excitation filter and a $515 \mathrm{~nm}$ emissions filter. The amount of fluorescent dye residue was then standardized for each bunch based on its total volume, and a mean value for the four clusters from each panel was calculated. One week after dye application, canopy structure was assessed via EPQA as described above. Spray coverage data were analyzed with simple linear regression/ANOVA.

Cluster exposure categorical relationships. Within the EPQA model, an individual CEFA value for every cluster contacted during the PQA assessment is calculated, and as a result every cluster contacted in the vineyard is provided a model-calculated PPF (\% PPF, relative to sunlight availability immediately outside the canopy); that is, CEFA $\mathrm{x} 100$. This feature was used to further analyze the relationship between sunlight exposure and powdery mildew development on clusters. First, disease rating data-individual vine or panel averages, as described above - for each vineyard (or specific fungicide treatment in the case of the Washington site) were ranked and separated into terciles, with the one-third of vines (or panels) with the lowest disease levels assigned to the first tercile and the one-third with the highest levels assigned to the third tercile (Table 2). The CEFA value for each cluster contacted during the PQA assessment of these same individual vines (or panels) was then used to categorize clusters as heavily shaded (0 to $10 \% \mathrm{PPF}$ ), moderately shaded/exposed (11 to $50 \% \mathrm{PPF}$ ); or well exposed (51 to $100 \%$ PPF). Finally, the proportion of that unit's clusters in each of the three shading categories was determined and averaged for all units in the first and third terciles. The means of these proportions within each shading category were compared between units in the first versus third tercile using Student's $t$-test.

\section{Results}

Washington State. Disease severity increased linearly in response to decreasing levels of sunlight exposure when no sulfur was applied (Figure 1), particularly in 2008, when both CEL and CEFA values provided similar strengths of association with disease severity measures (Table 3). However, comparisons of the predominant CEL values in 2008 versus 2009-ranging from $\sim 0.4$ to 1.6 versus 1.0 to 3.0 , respectively (Figure 1) - indicated that canopies were generally denser in the second year. Similarly, comparisons of CEFA values between 2008 and 2009, with predominant ranges of 0.1 to 0.4 versus 0.05 to 0.2 , respectively, indicated that only about one-half as much available sunlight was reaching the clusters in 2009 as in 2008 , with a narrow range of CEFA values across all vines. As a result, the relationship between disease severity and incremental changes in CEFA values was weak in 2009, whereas it remained strong for CEL values, which were distributed across a wider range. Furthermore, the greater potential availability of sunlight within canopies in 2008 was associated with a stronger response to incremental increases in exposure, as indicated by the relative slopes of the regression lines when data sets for a given spray treatment and EPQA measure were compared between the two years (Table 3).

Biweekly applications of $2 \mathrm{~kg} / \mathrm{ha}$ sulfur reduced disease severity by approximately two-thirds relative to the unsprayed vines in both seasons (Table 4). Even at this relatively low rate, the strength of the relationship between sunlight exposure and powdery mildew severity on fruit was weakened by the effects of sulfur, as indicated by the lower $\mathrm{R}^{2}$ values for the unsprayed treatment, as was the impact of incremental changes in exposure, as indicated by differences in the regression line slopes (Table 3). Nevertheless, a strong linear relationship remained between disease severity and sunlight exposure, as reflected by both CEL and CEFA values, for this treatment in 2008 (Figure 1, Table 3). However, when canopies were denser and sunlight penetration reduced in 2009, there was no association between CEFA values and disease severity

\begin{tabular}{|c|c|c|c|c|c|}
\hline & $\begin{array}{c}\text { Washington } \\
2008\end{array}$ & $\begin{array}{c}\text { Washington } \\
2009\end{array}$ & $\begin{array}{l}\text { New York } \\
2008\end{array}$ & $\begin{array}{l}\text { New York } \\
2009\end{array}$ & $\begin{array}{l}\text { Barossa } \\
2008-09\end{array}$ \\
\hline Seasonal degree days (base $10^{\circ} \mathrm{C}$ ) & 1364 & 1442 & 1332 & 1245 & 1697 \\
\hline Seasonal precipitation $(\mathrm{cm})$ & 4.50 & 4.62 & 61.06 & 55.98 & 15.21 \\
\hline Total solar irradiance $\left(\mathrm{MJ} / \mathrm{m}^{2}\right)$ & 4542 & 4824 & 3432 & 3382 & 4697 \\
\hline
\end{tabular}

Table 2 Tercile disease ranges and cluster counts used for percent photosynthetic photon flux (\% PPF) categorical comparisons at each location. The 1st tercile range is lowest one-third of all mean disease severity ratings for individual vines or panels (10 clusters/unit); the $3 \mathrm{rd}$ tercile range is highest one-third of all mean disease severity ratings. The data show the range of disease severity for the tercile in each experiment. Cluster count for each vineyard is the number of clusters for which a \%PPF was calculated by CEFA in the EPQA model.

\begin{tabular}{|c|c|c|c|c|c|c|c|c|c|c|}
\hline & $\begin{array}{l}\text { WA } 2008 \\
\text { (0 kg S) }\end{array}$ & $\begin{array}{l}\text { WA } 2008 \\
(2 \mathrm{~kg} \mathrm{~S})\end{array}$ & $\begin{array}{l}\text { WA } 2008 \\
(9 \mathrm{~kg} \mathrm{~S})\end{array}$ & $\begin{array}{l}\text { WA } 2009 \\
(0 \mathrm{~kg} \mathrm{~S})\end{array}$ & $\begin{array}{l}\text { WA } 2009 \\
(2 \mathrm{~kg} \mathrm{~S})\end{array}$ & $\begin{array}{l}\text { WA } 2009 \\
(9 \mathrm{~kg} \mathrm{~S})\end{array}$ & 008 & 009 & $\begin{array}{l}\text { Barossa } \\
2008-09\end{array}$ & $\begin{array}{c}\text { Riverland } \\
2008-09\end{array}$ \\
\hline 1st tercile & $13.4-43$ & $5.6-10.1$ & $0.3-3.8$ & $35.8-70.3$ & $3.1-13.2$ & $0.7-4.1$ & $17-44$ & $40-76.4$ & $0.3-2.2$ & $0.6-2.9$ \\
\hline 3rd tercile & $77-97.4$ & $29.8-65.3$ & $10.3-18.9$ & $88-97.7$ & $29.5-62.8$ & $10-15.6$ & $81.4-92.5$ & $92.6-94.4$ & $15.8-95.5$ & $21.2-88.5$ \\
\hline Cluster count & 1302 & 1294 & 1143 & 749 & 664 & 804 & 182 & 252 & 1009 & 305 \\
\hline
\end{tabular}



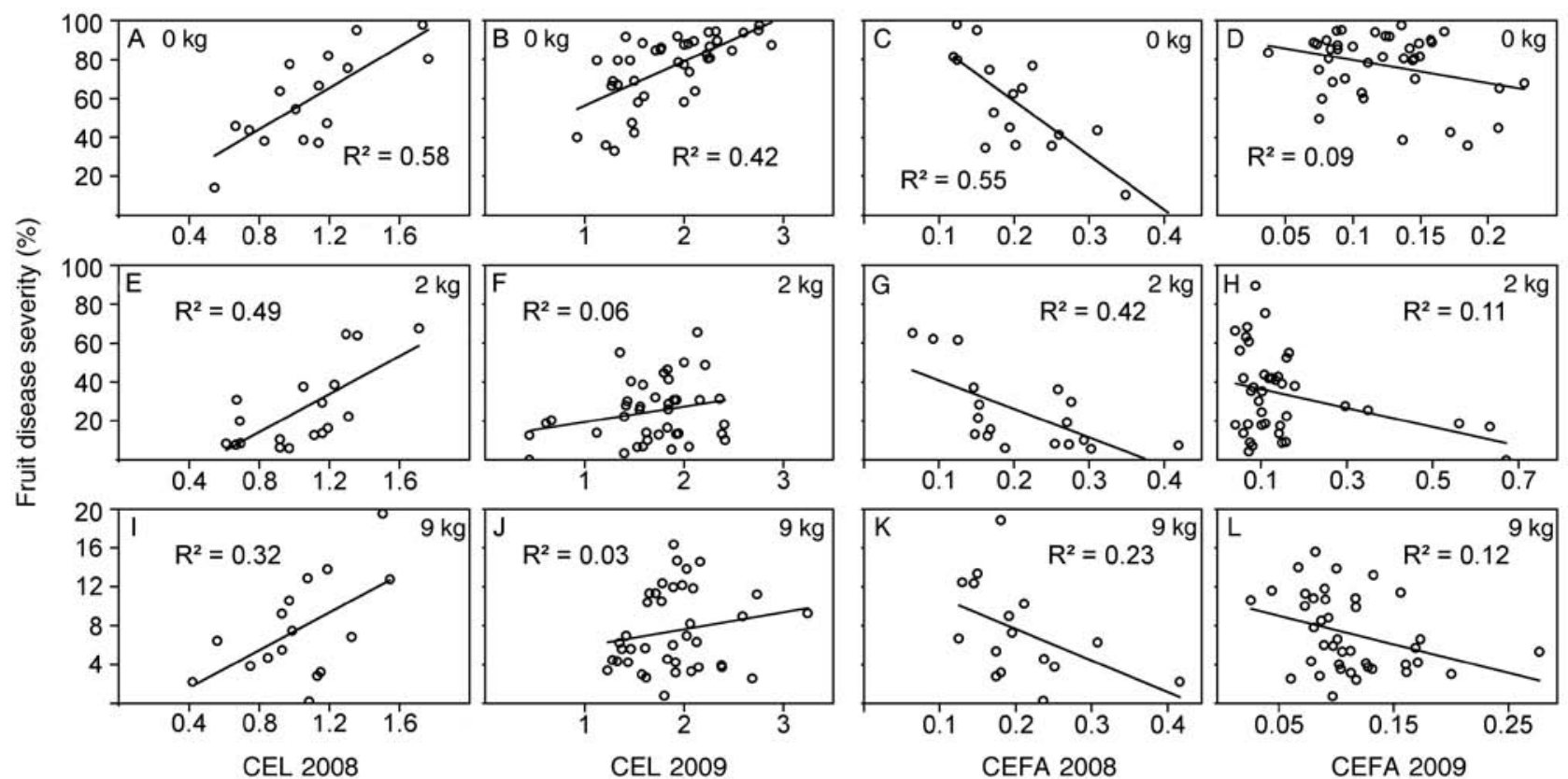

Figure 1 Powdery mildew severity on Chardonnay clusters in a Washington State vineyard as a function of cluster exposure layer (CEL), the number of shade layers between clusters and the nearest canopy boundary (A, B, E, F, I, J), and cluster exposure flux availability (CEFA), the proportion of abovecanopy photon flux that reaches clusters (C, D, G, H, K, L). Vines were subjected to three sulfur application regimes: unsprayed (A-D); treated biweekly with $2 \mathrm{~kg} / \mathrm{ha}(\mathrm{E}-\mathrm{H})$; or treated biweekly with $9 \mathrm{~kg} / \mathrm{ha} \mathrm{(I-L).} \mathrm{CEL,} \mathrm{CEFA,} \mathrm{and} \mathrm{disease} \mathrm{severity} \mathrm{values} \mathrm{were} \mathrm{assessed} \mathrm{on} 10$ Sept 2008 and 4 Aug 2009.

for vines treated with this low sulfur rate and, in stark contrast to the unsprayed vines, the association between disease severity and CEL values was very weak, suggesting that the effect of the sulfur applications outweighed that of the light exposure. Biweekly applications of the sulfur rate of $9 \mathrm{~kg} / \mathrm{ha}$ reduced overall disease severity by approximately an additional two-thirds relative to the $2 \mathrm{~kg}$ treatment (Table 4). In 2008, this increase in the sulfur rate further weakened the relationship between disease severity

Table 3 Statistical parameters for analyses of data from the Washington State vineyard, regressing fruit powdery mildew severity as a function of two different measures of exposure to sunlight.

\begin{tabular}{lcccl}
\hline Measure $^{a}$ & Treatment & $\mathbf{R}^{2}$ & Slope & \multicolumn{1}{c}{$\boldsymbol{p}$} \\
\hline $\mathbf{2 0 0 8}$ & & & & \\
CEL & $0 \mathrm{~kg} \mathrm{~S}$ & 0.58 & 52.07 & 0.0006 \\
CEL & $2 \mathrm{~kg} \mathrm{~S}$ & 0.49 & 47.37 & 0.0012 \\
CEL & $9 \mathrm{~kg} \mathrm{~S}$ & 0.32 & 9.46 & 0.023 \\
CEFA & $0 \mathrm{~kg} \mathrm{~S}$ & 0.55 & -278.0 & 0.0009 \\
CEFA & $2 \mathrm{~kg} \mathrm{~S}$ & 0.42 & -148.6 & 0.0035 \\
CEFA & $9 \mathrm{~kg} \mathrm{~S}$ & 0.23 & -32.68 & 0.05 \\
$\mathbf{2 0 0 9}$ & & & & \\
CEL & $0 \mathrm{~kg} \mathrm{~S}$ & 0.42 & 21.84 & $<0.0001$ \\
CEL & $2 \mathrm{~kg} \mathrm{~S}$ & 0.03 & 5.34 & 0.31 \\
CEL & $9 \mathrm{~kg} \mathrm{~S}$ & 0.03 & 1.70 & 0.26 \\
CEFA & $0 \mathrm{~kg} \mathrm{~S}$ & 0.09 & -118.4 & 0.06 \\
CEFA & $2 \mathrm{~kg} \mathrm{~S}$ & 0.06 & -28.45 & 0.14 \\
CEFA & $9 \mathrm{~kg} \mathrm{~S}$ & 0.12 & -29.37 & 0.03 \\
\hline
\end{tabular}

${ }^{a}$ Generalized linear model calculations for each Washington State season and sulfur treatment as function of cluster exposure layer (CEL; the number of shade layers between clusters and the nearest canopy boundary) and cluster exposure flux availability (CEFA; proportion of above-canopy photon flux that reaches clusters). and the impact of incremental changes in sunlight exposure, although it remained significantly linear for both of the EPQA measures ( $p=0.02$ and 0.05 for CEL and CEFA, respectively). There was little to no relationship between measures of cluster exposure and disease severity in the denser canopies of 2009 treated with the higher sulfur rate (Figure 1, Table 3).

New York State. In 2008, EPQA measurements in the Dresden vineyard were similar to those in the Washington vineyard, with CEL values generally $<2$ and CEFA values up to $\sim 0.4$ (Figure $2 \mathrm{~A}, \mathrm{C}$ ). CEL values in the Geneva vineyard in 2009 were similar to those in the Dresden vineyard the previous year; however, CEFA values indicated that a substantially lower proportion of available sunlight was reaching fruit in 2009, with values remaining $<0.25$ (Figure

Table 4 Cluster disease severity on Chardonnay vines receiving variable sulfur application regimes in two seasons in Washington State.

\begin{tabular}{lcc}
\hline & \multicolumn{2}{c}{ \% Cluster area diseased $\left(\%\right.$ control) $^{\mathrm{a}}$} \\
\cline { 2 - 3 } Treatment & $\mathbf{2 0 0 8}^{\mathrm{b}}$ & $\mathbf{2 0 0 9}^{\mathrm{c}}$ \\
\hline None & $59.3 \mathrm{a}(0)$ & $77.0 \mathrm{a}(0)$ \\
Sulfur, 2 kg/ha & $20.0 \mathrm{~b}(66.2)$ & $24.3 \mathrm{~b}(68.4)$ \\
Sulfur, 9 kg/ha & $7.4 \mathrm{c}(87.4)$ & $7.2 \mathrm{c}(90.7)$ \\
\hline
\end{tabular}

aMeans not followed by a common letter are significantly different according to the Tukey-Kramer HSD test $(p=0.05)$. Values in parentheses denote percent control relative to the untreated check. bMeans from 20 replicate plots per treatment, 10 clusters/plot. Sulfur applications: 673 L/ha on 19 Jun, 25 Jun, 9 Jul; 841 L/ha on 23 Jul, 7 Aug, 20 Aug, 2 Sept.

'Means from 40 replicate vines per treatment, 10 clusters/vine. Application: $580 \mathrm{~L} / \mathrm{ha}$ on $30 \mathrm{May} ; 767 \mathrm{~L} / \mathrm{ha}$ on $8 \mathrm{Jun}$; $963 \mathrm{~L} / \mathrm{ha}$ on 22 Jun; and $1346 \mathrm{~L} /$ ha on 6 Jul, 20 Jul, 3 Aug. 
2B, D). For both locations, the relationships between disease severity on clusters and the degree to which they were exposed to sunlight, as defined by CEL and CEFA values, was strongly linear (i.e., $p=0.003$ and 0.0005 , respectively, at Dresden and $p=0.03$ and 0.004 , respectively, at Geneva). At both sites, CEFA values provided the stronger association with disease severity. The number of buds retained per vine (i.e., 20, 40, or 60) during dormant pruning prior to the 2009 growing season was not a significant factor $(p=0.46)$ in relation to disease severity, as vines with fewer buds compensated with increased growth of the shoots that developed (Austin 2010). Nevertheless, the strong linear relationship between disease severity and CEFA and CEL values was maintained, regardless of bud number.

South Australia. Measured canopy densities in the Barossa Valley vineyard were similar to those in Washington State in 2009, that is, relatively high maximum CEL values of $\sim 3$ (Figure 3A). However, sunlight exposure on fruit within the canopy also was relatively high, with CEFA values up to $\sim 0.5$ (Figure $3 \mathrm{~B}$ ). The Riverland vineyard had fewer canopy layers than the Barossa Valley vineyard, with maximum CEL values of $\sim 2$ (Figure $3 \mathrm{C}$ ), although sunlight penetration into the fruit zone was weaker, providing maximum CEFA values of $\sim 0.3$ (Figure 3D). In both vineyards, the distribution of disease severities across CEL and CEFA values was far less even than in their North American counterparts. Therefore, vines were separated into two groups for further statistical comparisons (using Student's $t$-test), based on visual inspection of the data (Figure 3, Table 5). In the Barossa Valley, disease severity was significantly lower on vines with a CEL value $<1.5(p<0.0001)$ or a CEFA value $>0.2(p<0.0001)$ compared to those above and below these respective threshold values (Table 5). In Riverland, the training system did not have a significant effect $(p=0.44)$ on disease severity. Thus, data from these two treatments were pooled, and analysis showed there was

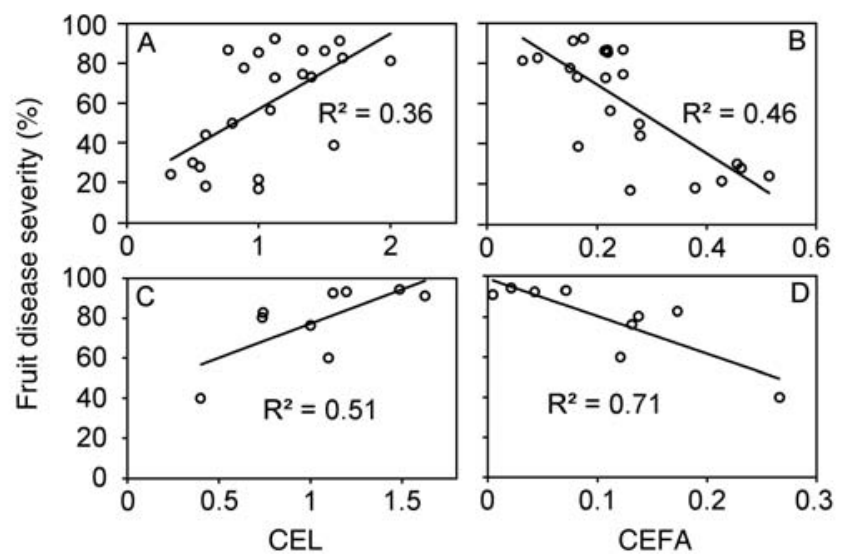

Figure 2 Powdery mildew severity in two Chardonnay vineyards in Dresden (A, B; 2008) and Geneva (C, D; 2009), New York, as a function of cluster exposure layer (CEL), the number of shade layers between clusters and the nearest canopy boundary $(\mathbf{A}, \mathbf{C})$, and cluster exposure flux availability (CEFA), the proportion of above-canopy photon flux that reaches clusters (B, D). CEL, CEFA, and disease severity values were assessed on 18 Aug 2008 and 9 Jul 2009. significantly less disease for vines with CEL values $<1.5$ ( $p$ $=0.004)$ or CEFA values $>0.2(p=0.03)$.

Categorical relationships. In the Washington vineyard in 2008, vines in the lowest tercile for cluster disease severity had significantly ( $p=0.05$ ) more clusters in the well-exposed category (51 to $100 \%$ PPF) than did those in the third tercile, for both the unsprayed and $2 \mathrm{~kg}$ sulfur treatments. Conversely, the third of the vines with the highest mean disease severities had significantly more heavily shaded clusters, regardless of fungicide treatment ( $p=0.04$, 0.02 , and 0.02 for the $0-, 2-$, and $9 \mathrm{~kg}$ treatments, respectively) (Figure 4A, C, E). Fewer significant differences were observed in the Washington vineyard in 2009, when proportional sunlight penetration into the canopy was generally lower than in 2008. However for unsprayed vines, those in the first disease tercile had significantly $(p=0.04)$ more well-exposed clusters than those in the third tercile. Also in 2009, the most-diseased vines in the $9 \mathrm{~kg}$ treatment had
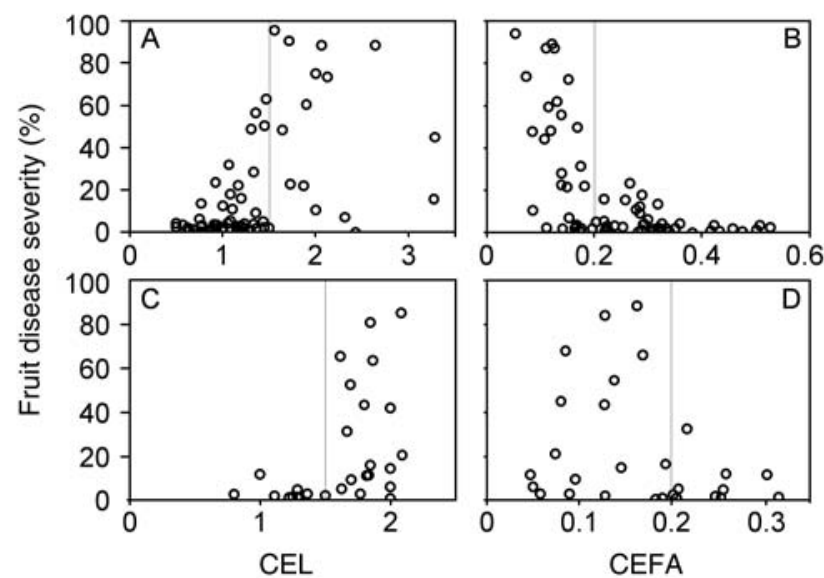

Figure 3 Powdery mildew severity in two Chardonnay vineyards in Barossa Valley (A, B) and in Riverland (C, D), South Australia, as a function of cluster exposure layer (CEL), the number of shade layers between clusters and the nearest canopy boundary $(\mathbf{A}, \mathbf{C})$, and cluster exposure flux availability (CEFA), the proportion of above-canopy photon flux that reaches clusters (B, D). CEL, CEFA, and disease severity values were assessed on 10 Feb 2009 in Barossa and 13 Feb 2009 in Riverland. Individual data points represent mean disease severity ratings for 10 clusters assessed on a single vine, and CEL and CEFA values represent the averages calculated from canopy assessments on the same vine.

Table 5 Categorical comparison of South Australian vineyards for disease severity on clusters separated on the basis of cluster exposure layer (CEL) and cluster exposure flux availability (CEFA) values.

\begin{tabular}{lcccccccc}
\hline & \multicolumn{3}{c}{ Barossa $^{\mathrm{a}}$} & & \multicolumn{3}{c}{ Riverland $^{\mathrm{a}}$} \\
\cline { 2 - 4 } \cline { 7 - 9 } EQPA value & $\mathbf{n}$ & Mean & Std. Er & & $\mathbf{n}$ & Mean & Std. Er \\
\hline CEL $\leq 1.5$ & 54 & 9.3 & 2.7 & & 10 & 3.1 & 7.4 \\
CEL $>1.5$ & 14 & 53.1 & 5.3 & & 18 & 32.4 & 5.6 \\
CEFA $\leq 0.2$ & 28 & 37.4 & 4.0 & & 18 & 30.0 & 6.0 \\
CEFA $>0.2$ & 40 & 5.0 & 3.6 & & 10 & 7.4 & 8.0 \\
\hline
\end{tabular}

andividual vines in each location were separated based on a mean CEL threshold value of 1.5 and a mean CEFA threshold value of 0.2 . Data refer to the total number $(n)$ of vines in each group and disease severity ratings for them. 
significantly more moderately or heavily shaded clusters than the least-diseased vines ( $p=0.05$ and 0.03 , respectively). This same pattern continued in the four other vineyards, wherein a significantly greater proportion of well-exposed clusters was found in the tercile of least-diseased vines and/ or a significantly greater proportion of heavily shaded clusters was found on the third of the vines with the highest disease severity ratings (Figure 4).

Spray coverage. There was a strong linear relationship between the shading of clusters as indicated by CEFA and CEL values and the spray deposit on them ( $p=0.0001$ and 0.012 , respectively). Within the range of mean canopy layers in the Geneva vineyard (0 to 2), spray deposition nearly doubled for each shading layer removed. Similarly, spray

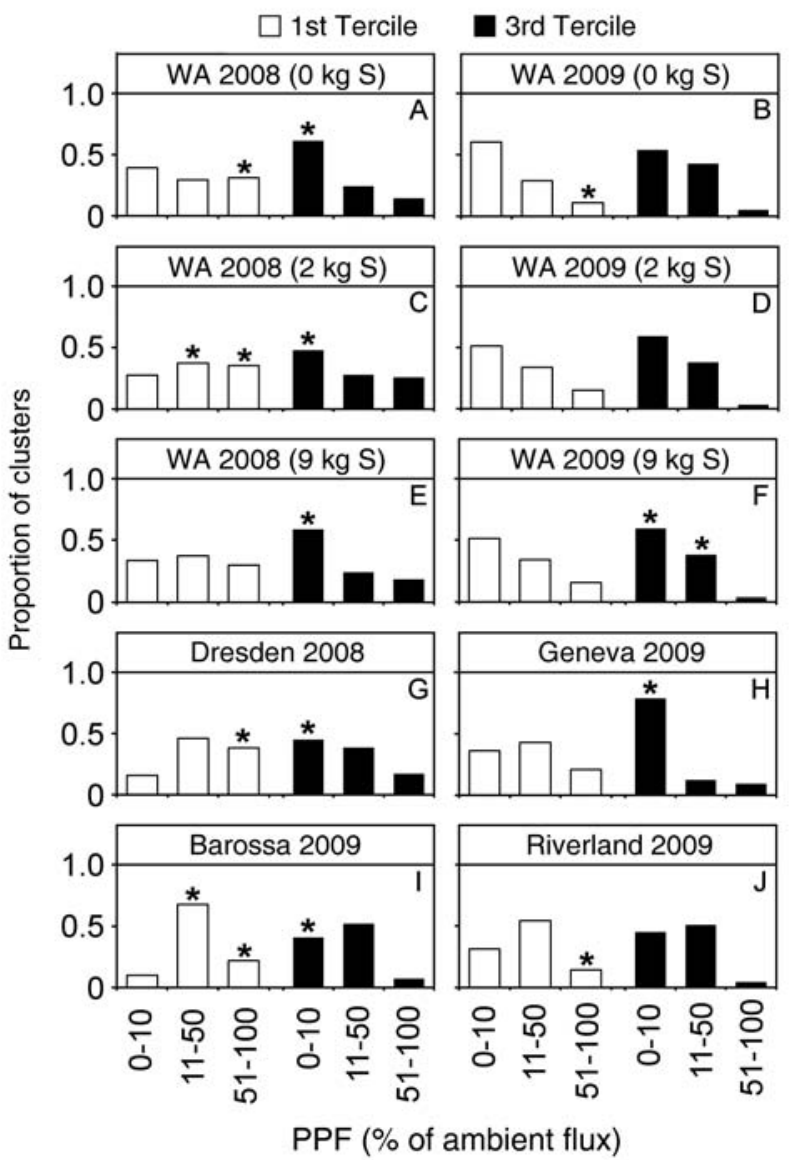

Figure 4 Categorical associations of fruit disease severity and shading level for all five vineyards. At each location, disease severity ratings for individual units (single vines or panels) were ranked: the first tercile of vines or panels was the one-third of the total number with the lowest severity ratings, while the third tercile was the one-third with the highest ratings. Photosynthetic photon flux (PPF) was calculated for every cluster contacted during PQA assessment and used to assign them to one of three shading categories: 0 to $10 \%$ PPF, 11 to $50 \%$ PPF, or 51 to $100 \%$ PPF. Finally, the proportion of that unit's clusters in each of the three shading categories was determined and averaged for all units in the first and third terciles. For each data set, the mean proportions for the three PPF categories were compared between the first and third tercile using Student's $t$-test $(p=0.05)$; columns with an asterisk $\left(^{*}\right)$ indicate a significantly greater proportion of clusters in that category relative to its tercile counterpart. See Table 2 for tercile disease ranges and numbers of clusters for which PPF was calculated and categorized. deposition increased by $\sim 50 \%$ for each $10 \%$ increase in proportional light penetration within the canopy (Figure 5).

\section{Discussion}

Although the impact of sunlight exposure on grape fruit chemistry has been extensively researched (Downey et al. 2006, Smart 1985), its impact upon powdery mildew development on berries has received little attention. This study, by using a single standard cultivar to reduce potential genetic sources of variability, has demonstrated a consistent and quantitative relationship between disease severity and sunlight exposure levels in five different vineyards in regions as diverse as New York, Washington, and South Australia. Furthermore, we have quantified, using EPQA, the heretofore-presumed effect that canopy density exerts on the deposition of spray materials onto developing clusters and have shown that canopy density can influence powdery mildew development through its interactive effects on both the host-pathogen interaction itself and fungicide coverage of the clusters.

In the relatively cool and humid New York vineyards, there was a strong linear relationship between disease severity on clusters and their degree of exposure to sunlight, as measured both directly (CEFA) and indirectly (CEL). The Washington State vineyard was in a significantly warmer, drier climate that provided substantially more sunlight than in New York, yet on unsprayed vines, there were similar linear relationships between fruit disease severity and sunlight exposure within the fruit zone. Sunlight attenuation within the fruit zone was stronger in 2009

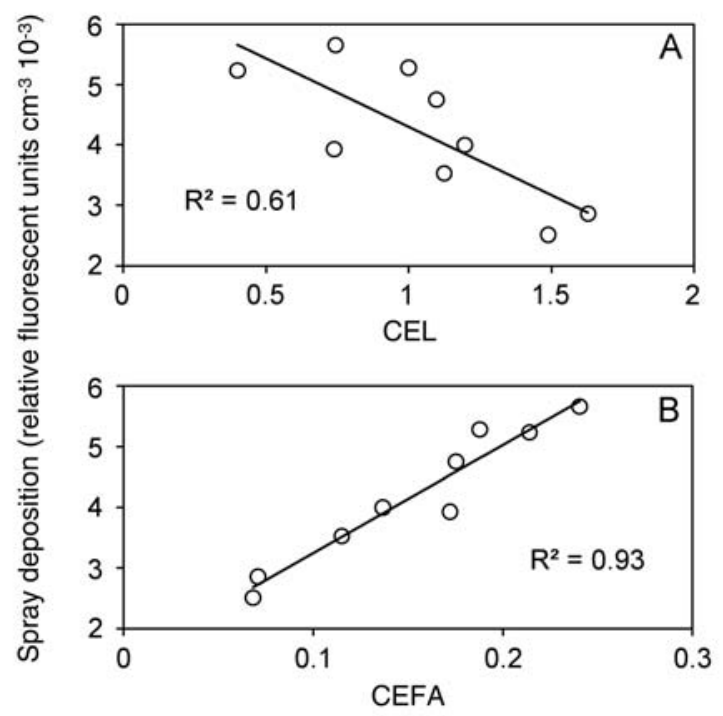

Figure $\mathbf{5}$ Spray deposition as a function of $(\mathbf{A})$ cluster exposure layer and (B) cluster exposure flux availability in the Geneva vineyard subjected to different canopy management treatments. Fluorescent dye was applied 4 weeks postbloom. Intact clusters were collected immediately after sprays had dried and assessed in the lab for the quantity of dye per unit volume of the bunch. Each vine was assessed one week after dye application via enhanced point quadrat analysis (EPQA) to establish fruit-zone exposure levels to sunlight. Individual data points represent mean standardized values for spray coverage assessed on four clusters from each of nine individual panels; corresponding CEL and CEFA values represent averages of four EPQA-assessed vines per panel. 
than in 2008, with correspondingly weaker relationships between measures of cluster exposure and disease severity.

In South Australia, where UV radiation levels are considered particularly high, there was a strong impact of sunlight on fruit disease severity; however, these relationships were not linear as in the northern hemisphere vineyards. In the Australian vineyards, little disease developed on vines with a CEFA value $>0.2$ or a $\mathrm{CEL}$ value $<1.5$, whereas all moderately to heavily diseased clusters occurred on vines with measured values below and above these putative thresholds, respectively. In all vineyards, the third of the vines with the lowest disease ratings consistently had the highest proportion of their clusters classified as wellexposed (51 to $100 \%$ PPF), whereas conversely, the third with the highest disease ratings had the highest proportion of their clusters in the heavily shaded $(<10 \%$ PPF) category. This relationship notwithstanding, levels of cluster exposure ideal for powdery mildew control might also result in the sunburn of fruit; hence, truly optimal exposure levels must integrate various factors to account for specific considerations unique to each region and producer.

In addition to vineyard and canopy management practices that incrementally influence sunlight intensity in the fruit zone-and, thus, cluster disease severity-external factors may also affect the intensity of powdery mildew development. The potential impact of transient and irregular shading factors affecting entire vineyards or districts, such as prolonged periods of heavy cloud cover associated with rainy portions of the growing season, is perhaps lacking appreciation among many grapegrowers and advisors. This applies not only to identifying the relative seasonal risk in regions such as New York, where weather can vary considerably from one year to the next, but also to identifying unanticipated risks in unusually cloudy years or critical portions thereof, such as when fruit are highly susceptible to powdery mildew shortly after bloom (Gadoury et al. 2003), in regions such as Washington State and South Australia that are typically sunny. Existing climate-based models intended to indicate powdery mildew risk (Gubler et al. 1999, Sall 1980) might be enhanced by including a component to account for variable levels of solar radiation, although this has yet to be fully quantified.

In most of these present experiments, as in Zahavi et al. 2001, vines were left unsprayed in order to examine the effect of canopy density on powdery mildew development. Whereas this technique is useful for examining the effect of sunlight on disease per se, it does not reflect typical commercial vineyard conditions. Thus, in Washington the interactive effects of canopy density and fungicide applications were examined, using wettable sulfur at both a relatively low and high rate within the range used by U.S. growers. Here, the effect of the sulfur itself dampened the influence of sunlight exposure on disease severity, and these exposure effects were reduced even more at the higher of the two application rates. Nevertheless, significant quantitative relationships remained between fruit disease severity and both EPQA measures of cluster exposure. In such an experiment, it is not possible to distinguish the direct effects of sunlight on the host-pathogen interaction resulting from increased cluster exposure versus the indirect effects that increased exposure might have on sulfur activity. The Geneva vineyard trial clearly demonstrated a two-fold difference in spray deposition on clusters as a function of canopy densities within the relatively narrow range examined, thereby quantifying the well-accepted assumption of higher pesticide residue on well-exposed fruit. Furthermore, warming of tissues exposed to sunlight likely can increase the volatility of sulfur within an open canopy, providing further suppressive effects on powdery mildew development. These results not only demonstrate the rate at which spray coverage increases in response to canopy layers and sunlight exposure but also link the interactive effect that canopy structure has on the disease-suppressive activities of sunlight and fungicide applications. Open canopy structures may influence disease development through their effects on other relevant environmental parameters, such as relative humidity (Carroll and Wilcox 2003), although we were unable to detect such differences with the technology used for measuring mesoclimate parameters (Austin 2010). Regardless of the mechanism involved, these results demonstrate that improved powdery mildew control is yet another benefit to be derived from canopy management practices designed to optimize sunlight exposure of the clusters.

Various methods have been developed to assess canopy structure and sunlight distribution on fruit, although they vary in their ease of use and high-throughput applicability (Smart and Robinson 1991, Schultz 1995, Gladstone and Dokoozlian 2003, Meyers and Vanden Heuvel 2008). There is a balance between ease of use and precision of the resulting output, which should guide the choice or development of the method used for any particular purpose. The EPQA method of canopy mapping provides the ability to assess rapidly hundreds of vines in one day and to provide detailed information on sunlight exposure of fruit (Meyers and Vanden Heuvel 2008). EPQA further provides the ability to calculate PPF proportions for individual clusters within a vine and diagnose vines with high degrees of shaded fruit within the vineyard. For example, based on results here, vines with high levels of heavily shaded clusters (i.e., those receiving $<10 \%$ PPF) could be identified as high risk vines for powdery mildew development. Precision viticulture approaches that use technologies such as GIS and GPS have been proposed (Reynolds et al. 2007, Hall et al. 2002) to improve management of blocks or subregions within a vineyard for uniformity of flavor, color, and yield and could also be adapted to powdery mildew management. Software programs (Hall et al. 2003, Delenne et al. 2010) that use technologies such as NDVI imaging and aerial photography could be correlated with ground measures of canopy structure, and entire vineyard disease risk assessments could thereby be made on an individual vine basis. These assessments have the potential to incorporate precision disease management into precision viticulture and to improve proactive management of this widespread disease. 


\section{Conclusion}

Variable sunlight penetration into the fruit zone, either via natural variation in vine vigor or cultural practices such as pruning, alters the development of powdery mildew on clusters, with disease severity inversely proportional to the degree of sunlight exposure provided. Variation in canopy architecture also can influence disease development through an effect on the deposition of fungicides applied to control the disease, with spray deposits directly proportional to the extant degree of cluster exposure. Thus, canopy structures improving sunlight penetration into the fruit zone inhibit disease development through the dual effects of sunlight exposure on the host-pathogen interaction and improved pesticide deposition. Canopy structure assessment through methods such as EPQA allows for rapid and informative determination of individual vine fruit exposure. These results show the utility of canopy management as a component of an integrated disease management program and may assist in better determination of powdery mildew risk for specific locations and/or vines.

\section{Literature Cited}

Austin, C.N. 2010. Sunlight's influence on grapevine powdery mildew: Direct effects on pathogen development and attendant consequences of canopy management and vineyard variability. Ph.D. dissertation, Cornell University, New York.

Austin, C.N., A.N. Lakso, R.C. Seem, D.G. Riegel, and W.F. Wilcox. 2009. Inhibition of powdery mildew by improved vineyard sunlight exposure. Abstract. Am J. Enol. Vitic. 60:396A.

Björn, L.O. 2007. Stratospheric ozone, ultraviolet radiation, and cryptogams. Biol. Conserv. 135:326-333.

Carroll, J.E, and W.F. Wilcox. 2003. Effects of humidity on development of grapevine powdery mildew. Phytopathology 93:1137-1144.

Chellemi, D.O., and J.J. Marois. 1992. Influence of leaf removal, fungicide applications, and fruit maturity on incidence and severity of grape powdery mildew. Am. J. Enol. Vitic. 43:53-57.

Chen, L.S., P. Li, and L. Cheng. 2009. Comparison of thermotolerance of sun-exposed peel and shaded peel of 'Fuji' apples. Environ. Exp. Botany. 66:110-116.

Delenne, C., S. Durrieu, G. Rabatel, and M. Deshayes. 2010. From pixel to vine parcel: A complete methodology for vineyard delineation and characterization using remote-sensing data. Comput. Electron. Agric. 70:78-83.

Delp, C. 1954. Effect of temperature and humidity on the grape powdery mildew fungus. Phytopathology 44:615-626.

Downey, M.O., N.K. Dokoozlian, and M.P. Krstic. 2006. Cultural practice and environmental impacts on the flavonoid composition of grapes and wine: A review of recent research. Am. J. Enol. Vitic. 57:257-268.

Ferguson, I.B., W. Snelgar, M. Lay-Yee, C.B. Watkins, and J.H. Bower. 1998. Expression of heat shock protein genes in apple fruit in the field. Aust. J. Plant Physiol. 25:155-163.

Gadoury, D.M., R.C. Seem, A. Ficke, and W.F. Wilcox. 2003. Ontogenic resistance to powdery mildew in grape berries. Phytopathology 93:547-555

Gladstone, E.A., and N.K. Dokoozlian. 2003. Influence of leaf area density and trellis/training system on the light microclimate within grapevine canopies. Vitis 42:123-131.

Gubler, W.D., M.R. Rademacher, S.J. Vasquez, and C.S. Thomas. 1999. Control of powdery mildew using the UC Davis powdery mildew risk index. APSnet Feature. American Phytopathological Society, St. Paul, MN.
Hall, A., D.W. Lamb, B. Holzaphel, and J. Louis. 2002. Optical remote sensing applications in viticulture-A review. Aust. J. Grape Wine Res. 8:36-47.

Hall, A., J. Louis, and D. Lamb. 2003. Characterizing and mapping vineyard canopy using high-spatial-resolution aerial multispectral images. Comput. Geosci. 29:813-822.

Keller, M. 2010. Managing grapevines to optimize fruit development in a challenging environment: A climate change primer for viticulturists. Aust. J. Grape Wine Res. 16:56-69.

Keller, M., S.Y. Rogiers, and H.R. Schultz. 2003. Nitrogen and ultraviolet radiation modify grapevines' susceptibility to powdery mildew. Vitis 42:87-94.

Keller, M., and N. Torres-Martinez. 2004. Does UV radiation affect winegrape composition? Acta Hortic. 640:313-319.

Kliewer, W.M., and L.A. Lider. 1968. Influence of cluster exposure to the sun on the composition of Thompson Seedless fruit. Am. J. Enol. Vitic. 19:175-184.

Kolb, C.A., M.A Kaser, J. Kopecky, G. Zotz, M. Riederer, and E.E. Pfundel. 2001. Effects of natural intensities of visible and ultraviolet radiation on epidermal ultraviolet screening and photosynthesis in grape leaves. Plant Physiol. 127:863-875.

Manning, W.J., and A. von Tiedemann. 1995. Climate change: Potential effects of increased atmospheric carbon dioxide $\left(\mathrm{CO}_{2}\right)$, ozone $\left(\mathrm{O}_{3}\right)$, and ultraviolet-B (UV-B) radiation on plant diseases. Environ. Pollut. 88:219-245.

Meyers, J.M., and J.E. Vanden Heuvel. 2008. Enhancing the precision and spatial acuity of point quadrat analyses via calibrated exposure mapping. Am. J. Enol. Vitic. 59:425-431.

Millar, A.A. 1972. Thermal regime of grapevines. Am. J. Enol. Vitic. 23:173-176.

Moody, S.A., et al. 2001. The direct effects of UV-B radiation on Betula pubescens litter decomposing at four European field sides. Plant Ecol. 154:27-36.

Reynolds, A.G., I.V. Senchuk, C. van der Reest, and C. de Savigny. 2007. Use of GPS and GIS for elucidation of the basis for terroir: Spatial variation in an Ontario Riesling vineyard. Am. J. Enol. Vitic. 58:145-162.

Roberts, M.R., and N.D. Paul. 2006. Seduced by the dark side: Integrating molecular and ecological perspectives on the influence of light on plant defense against pests and pathogens. New Phytol. 170:677-699.

Rotem, J., B. Wooding, and D.E. Aylor. 1985. The role of solar radiation, especially ultraviolet, in the mortality of fungal spores. Phytopathology 75:510-514.

Sall, M.A. 1980. Epidemiology of grape powdery mildew: A model. Phytopathology 70:338-342.

Schroeder, C.A. 1965. Temperature relationships in fruit tissues under extreme conditions. Proc. Am. Soc. Hortic. Sci. 87:199-203.

Schultz, H.R. 1995. Grape canopy structure, light microclimate and photosynthesis. I. A two-dimensional model of the spatial distribution of surface area densities and leaf ages in two canopy systems. Vitis 34:211-215.

Smart, R.E. 1985. Principles of grapevine canopy microclimate manipulation with implications for yield and quality. A review. Am. J. Enol. Vitic. 36:230-239.

Smart, R., and M. Robinson. 1991. Sunlight into Wine: A Handbook for Winegrape Canopy Management. Winetitles, Adelaide.

Smart, R.E., and T.R. Sinclair. 1976. Solar heating of grape berries and other spherical fruits. Agric. Meteorol. 17:241-259.

Willocquet, L., D. Colombet, M. Rougier, J. Fargues, and M. Clerjeau. 1996. Effects of radiation, especially ultraviolet B, on conidial germination and mycelial growth of grape powdery mildew. Eur. J. Plant. Pathol. 102:441-449.

Zahavi, T., M. Reuveni, D. Scheglov, and S. Lavee. 2001. Effect of grapevine training systems on development of powdery mildew. Eur. J. Plant Pathol. 107:495-501. 